\title{
HUBUNGAN HYGIENE PERORANGAN DAN PEMAKAIAN ALAT PELINDUNG DIRI DENGAN KEJADIAN INFEKSI KECACINGAN PADA PEMULUNG SAMPAH DI TPA TAMANGAPA KOTA MAKASSAR Andi Ruhban ${ }^{1}$ dan Andi Mennie Tri Rahayu². \\ 1.2Poltekkes Kemenkes Makassar andimennitrirahayu07@gmail.com
}

\begin{abstract}
In Indonesia the prevalence of worm disease is still high that is $45-46 \%$. In certain areas with poor sanitation, the prevalence of worms can reach $80 \%$. Infections occur due to ingested eggs of worms and contaminated soil or from active penetration through the skin by ground larvae. High-risk groups infected with diseases such as wound scavenging communities. The purpose of this research is to know the correlation between individual hygiene and the use of personal protective equipment with the occurrence of infection of worms at garbage scavengers in TPA Tamangapa Makassar City. The research design of this research is a cross-sectional sample of 73 stool samples and 73 respondents, the sample is selected by purposive sampling. Individual hygiene data and the use of personal equipment in scavengers were obtained through direct observation based and observation questionnaires, while data on the occurrence of infectious infection were obtained from laboratory examination results. Data were analyzed by correlation of the chi-square test. The statistical test shows that the bathing habit variable $(p=0,639)$ is greater than $p>0,05$, so HO is accepted. Meanwhile, handwashing habit $(p=0,000)$, nail cutting behavior $(p=0,000)$, and use of personal protective equipment $(p=0,004)$, less than $p<0,05$, so Ha is accepted. The results of almost all samples (99\%) have worm eggs. This study concludes that worm infection is not associated with bathing habits, however, it is associated with handwashing, nail cutting, and personal protective equipment. For that it is expected for garbage scavengers, to pay attention to individual hygiene when finished working in Final Disposal Place of the Tamangapa City of Makassar.
\end{abstract}

Keywords: Hygiene Personal, Use of Personal Protective Equipment, Occurrence of Worm Infection, Waste Scavenger

\section{ABSTRAK}

Di Indonesia prevelansi penyakit kecacingan masih tinggi ,yaitu 45-46\%. Di wilayah-wilayah tertentu dengan sanitasi buruk ,prevalansi kecacingan dapat mencapai $80 \%$. Infeksi terjadi oleh karena tertelan telur cacing dari tanah yang terkontaminasi atau dari penetrasi aktif melalui kulit oleh larva ditanah. Kelompok yang berisiko tinggi terinfeksi penyakit kecacingan diantaranya komunitas pemulung sampah. Tujuan penelitian ini adalah untuk mengetahui hubungan hygiene perorangan dan pemakaian alat pelindung diri dengan kejadian infeksi kecacingan pada pemulung sampah di TPA Tamangapa Kota Makassar. Jenis penelitian pada penelitian ini adalah cross-sectional. Jumlah sampel 73 sampel tinja dan 73 responden, sampel dipilih secara purposive sampling. Data hygiene perorangan dan pemakaian APD pada pemulung diperoleh melalui pengamatan secara langsung berdasarkan kuesioner pengamatan, sedangkan data kejadian infeksi kecacingan diperoleh dari hasil pemeriksaan Laboratorium. Data dianalisis dengan korelasi uji chi square. Uji statistik menunjukkan bahwa variabel kebiasaan mandi $(p=0,639)$ yang lebih besar nilainya dari $p>0,05$, sehingga $H 0$ diterima. Sedangkan, variabel kebiasaan mencuci tangan $(p=0,000)$, kebiasaan memotong kuku $(p=0,000)$, dan pemakaian APD $(p=0,004)$, yang lebih kecil dari $p<0,05$, sehingga Ha diterima. Hasil penelitian hampir semua sampel $(99 \%)$ terdapat telur cacing. Kesimpulan dari penelitian ini adalah infeksi kecacingan tidak berhubungan dengan kebiasaan mandi, akan tetapi, berhubungan dengan kebiasaan mencuci tangan, kebiasaan memotong kuku, dan pemakaian APD. Untuk itu diharapkan bagi pemulung sampah, agar memperhatikan hygiene perorangan saat selesai bekerja di Tempat Pembuangan Akhir sampah Tamangapa Kota Makassar.

Kata kunci: Hygiene Perorangan, Alat Pelindung Diri, Kejadian Infeksi Kecacingan, Pemulung Sampah

\section{PENDAHULUAN}

Sebagai Negara berkembang, Indonesia masih menghadapi masalah tingginya prevalensi penyakit infeksi terutama yang berkaitan dengan kondisi sanitasi lingkungan yang belum baik. Salah satu penyakit yang insidennya masih tinggi adalah infeksi kecacingan yang merupakan salah satu penyakit berbasis lingkungan. Hal tersebut dapat dimengerti mengingat bahwa Indonesia adalah Negara agraris dengan tingkat social ekonomi,pengetahuan,keadaan sanitasi lingkungan dan hygiene masyarakat yang masih rendah yang sangat mendukung untuk terjadinya infeksi dan penularan cacing (Rizka,Nuzulia,dan Machdawaty,2013).

Menurut WHO (2011), penyakit infeksi paling umum menyerang kelompok masyarakat ekonomi lemah dan ditemukan pada berbagai golongan usia. Kelompok yang berisiko tinggi terinfeksi penyakit kecacingan diantaranya komunitas pemulung sampah. Pemulung sampah dapat terinfeksi telur cacing apabila pemulung jarang memperhatikan personal hygiene, infeksi tersebut dapat masuk melalui kuku yang tidak bersih,tidak mencuci tangan sebelum makan dan tidak menggunakan alat pelindung diri berupa sepatu both sebagai alas kaki dan sarung tangan dan pakaian panjang saat bekerja karena pemulung sampah selalu kontak dengan tanah dimana tumpukan sampah di TPA khususnya sampah organic yang membasahi tanah akan mempercepat proses pembusukan sampah menjadi humus.Kondisi ini menyebabkan tanah menjadi lebih berongga dan memiliki kelembaban yang cukup sehingga mendukung untuk perkembangan cacing pada tanah. 
Jurnal Sulolipu : Media Komunikasi Sivitas Akademika dan Masyarakat

Vol. 18 No 22018

e-issn : 2622-6960, p-issn: 0854-624X

Menurut WHO (2015) bahwa jumlah kasus infeksi STH (Soil Transmitted Helmint) terbanyak di kawasan Sub-Sahara Afrika,Benua Amerika,Cina dan Asi Timur.Di Indonesiapun prevelansi penyakit kecacingan masih tinggi ,yaitu 45-46\%.Di wilayahwilayah tertentu dengan sanitasi buruk ,prevalansi kecacingan dapat mencapai $80 \%$. Berdasarkan data dari Puskesmas Tamangapa diperoleh data infeksi kecacingan pada tahun 2015 yaitu sebanyak 42 kasus infeksi kecacingan, tahun 2016 sebanyak 15 kasus infeksi kecacingan dan tahun 2017 sebanyak 13 kasus infeksi kecacingan.Meskipun tingkatan 10 penyakit tertinggi pada Puskesmas Tamangapa penyakit infeksi kecacingan tidak termasuk dalam 10 penyakit tertinggi, tetapi dilihat dari data infeksi kecacingan tersebut dapat dikatakan bahwa penyakit kecacingan cukup banyak diderita oleh masyarakat.Berdasarkan keterangan yang didapatkan dari pegawai Puskesmas bahwa Infeksi kecacingan sering diabaikan oleh para masyarakat karena kurang mengerti penyebab,gejala dan dampak dari Infeksi kecacingan.

Berdasarkan latar belakang diatas maka penulis tertarik melakukan penelitian dengan mengangkat sebuah judul penelitian yaitu Hubungan Hygiene Perorangan dan Pemakaian Alat Pelindung Diri dengan Kejadian Infeksi Kecacingan pada Pemulung Sampah di TPA Tamangapa Kota Makassar.

\section{BAHAN DAN METODE}

1. Lokasi Penelitian:

Penelitian ini berlokasi di TPA Tamangapa Antang Kecamatan Manggala Kota Makassar.Tempat pembuangan Akhir (TPA) di Makassar yang terletak di kelurahan Tamangapa Antang Kec.Manggala Kota Makassar.Tempat Pembuangan Akhir ini memiliki luas 14,3 $\mathrm{Ha}$.

\section{Desain dan Variabel Penelitian}

Jenis penelitian yang digunakan adalah penelitian survei analitik dengan pendekatan cross sectional dimana variabel bebas dan variabel terikat dibandingkan secara bersamaan guna mengetahui hubungan antara variabel-variabel tersebut.

Adapun variabel penelitian pada penelitian ini terdiri dari 3 variabel. Yaitu variabel bebas yang terdiri dari Hygiene Perorangan seperti memotong kuku,mencuci tangan sebelum/sesudah makan, dan kebiasaan mandi, serta pemakaian alat pelindung diri seperti menggunakan sarung tangan,menggunakan pakaian panjang dan menggunakan sepatu boots, variabel terikat yaitu kejadian infeksi kecacingan, serta variabel pengganggu yang terdiri dari pendidikan dan social ekonomi.

3. Populasi dan Sampel

Populasi dalam penelitian ini adalah para pemulung sampah yang bekerja di TPA Tamangapa Kecamatan Manggala Kota Makassar yaitu sebanyak 300 orang.

Sampel dalam penelitian ini adalah pemulung sampah yang berumur 10 tahun keatas,berdomisili di Kel.Tamangapa Kec.Manggala,serta telah menjadi pemulung sampah lebih dari 1 bulan .Jumlah sampel yaitu 73 orang.Pengambilan Data dilakukan menggunakan Metode Random Sampling.

\section{Pengumpulan data}

Sumber data terdiri dari 2 yaitu Data primer diperoleh dari hasil observasi langsung dan wawancara menggunakan lembar kuesioner serta hasil pemeriksaan telur cacing pada tinja dari laboratorium parasitologi dan data sekunder yang diperoleh dari sumber lain seperti, laporan pemerintah, buku, jurnal, dan karya tulis ilmiah.

5. Analisa Data (Jika memakai program statistic, tuliskan uji utama apa yang digunakan)

Analisis univariate dilakukan untuk mendeskripsikan variabel bebas yaitu: hygiene perorangan dan pemakaian alat pelindung diri.

Analisis bivariate dilakukan terhadap dua variabel yang diduga berhubungan. Analisis ini menggunakan uji statistik dengan program Statistic Product and Service Solutions (SPSS) berupa Uji chi-square

HASIL

1. Kebiasaan Memotong Kuku Tabel 1

Distribusi Responden Berdasarkan Kebiasaan Memotong Kuku pada Pemulung Sampah

\begin{tabular}{cccc}
\hline $\begin{array}{c}\mathbf{N} \\
\text { o. }\end{array}$ & $\begin{array}{c}\text { Kebiasaan } \\
\text { Memotong Kuku }\end{array}$ & $\begin{array}{c}\text { Pemulung Sampah } \\
\text { Frekuensi }\end{array}$ & $\begin{array}{c}\text { Persentase } \\
(\%)\end{array}$ \\
\hline 1. & Baik & 2 & $3 \%$ \\
2. & Cukup & 58 & $79 \%$ \\
3. & Kurang & 13 & $18 \%$ \\
\hline & Total & $\mathbf{7 3}$ & $\mathbf{1 0 0} \%$ \\
\hline
\end{tabular}

Sumber : Data Primer 2018 
Jurnal Sulolipu : Media Komunikasi Sivitas Akademika dan Masyarakat

Vol. 18 No 22018

e-issn : 2622-6960, p-issn: 0854-624X

Tabel 2

Hubungan Kebiasaan Memotong Kuku Dengan Infeksi Kecacingan Pada Pemulung Sampah

\begin{tabular}{lccccccc}
\hline $\begin{array}{l}\text { Kebiasaan } \\
\text { Memotong } \\
\text { Kuku }\end{array}$ & $\begin{array}{c}\text { Kegatif } \\
\text { Kecacingan } \\
(-)\end{array}$ & $\begin{array}{c}\text { Positif } \\
(+)\end{array}$ & Total & & $\boldsymbol{P}$ \\
& $\mathbf{N}$ & $\mathbf{n}$ & $\%$ & $\mathbf{N}$ & $\%$ & \\
\hline Baik & 1 & 50 & 1 & 50 & 2 & 100 & \\
Cukup & 0 & 0 & 58 & 100 & 58 & 100 & 0,000 \\
Kurang & 0 & & 13 & 99 & 13 & 100 & \\
& & 0 & & & & & \\
\hline Total & $\mathbf{1}$ & $\mathbf{1}$ & $\mathbf{7 2}$ & $\mathbf{9 9}$ & $\mathbf{7 3}$ & $\mathbf{1 0 0}$ & \\
\hline
\end{tabular}

Sumber : Data Primer 2018

\section{Kebiasaan Mencuci Tangan}

Tabel 3

Distribusi Responden Berdasarkan Kebiasaan Mencuci Tangan pada Pemulung Sampah

\begin{tabular}{cccc}
\hline No. & $\begin{array}{c}\text { Kebiasaan } \\
\text { Mencuci } \\
\text { Tangan }\end{array}$ & $\begin{array}{c}\text { Pemulung Sampah } \\
\text { Frekuensi }\end{array}$ & $\begin{array}{c}\text { Persentase } \\
(\%)\end{array}$ \\
\hline 1. & Baik & 4 & $6 \%$ \\
2. & Cukup & 50 & $68 \%$ \\
3. & Kurang & 19 & $26 \%$ \\
\hline & Total & $\mathbf{7 3}$ & $\mathbf{1 0 0} \%$ \\
\hline
\end{tabular}

Sumber: Data Primer 2018

Tabel 4

Hubungan Kebiasaan Mencuci Tangan dengan Infeksi Kecacingan pada Pemulung Sampah

\begin{tabular}{|c|c|c|c|c|c|c|c|}
\hline \multirow{3}{*}{$\begin{array}{c}\text { Kebiasaan } \\
\text { Mencuci } \\
\text { Tangan }\end{array}$} & \multicolumn{4}{|c|}{$\begin{array}{c}\text { Infeksi } \\
\text { Kecacingan }\end{array}$} & \multicolumn{2}{|c|}{ Total } & \multirow[t]{3}{*}{$\boldsymbol{P}$} \\
\hline & \multicolumn{2}{|c|}{$\begin{array}{c}\text { Negatif } \\
(-)\end{array}$} & \multicolumn{2}{|c|}{$\begin{array}{l}\text { Positif } \\
(+)\end{array}$} & \multirow[b]{2}{*}{$\mathbf{N}$} & \multirow[b]{2}{*}{$\%$} & \\
\hline & $\mathbf{n}$ & $\%$ & $\mathbf{N}$ & $\%$ & & & \\
\hline Baik & 1 & 25 & 3 & 75 & 4 & 100 & \\
\hline Cukup & 0 & 0 & 50 & 100 & 50 & 100 & 0,000 \\
\hline Kurang & 0 & & 19 & 99 & 19 & 100 & \\
\hline & & 1 & & & & & \\
\hline Total & 1 & 1 & 72 & 99 & 73 & 100 & \\
\hline
\end{tabular}


Jurnal Sulolipu : Media Komunikasi Sivitas Akademika dan Masyarakat

Vol. 18 No 22018

e-issn : 2622-6960, p-issn: 0854-624X

\section{Infeksi Kecacingan}

Tabel 9

Distribusi Responden yang Terinfeksi Telur Cacing Pada Pemulung Sampah

\begin{tabular}{cccc}
\hline No. & $\begin{array}{c}\text { Infeksi } \\
\text { Telur } \\
\text { Cacing }\end{array}$ & Frekuensi & $\begin{array}{c}\text { Pemulung Sampah } \\
\text { Persentase } \\
(\%)\end{array}$ \\
\hline 1. & Positif $(+)$ & 72 & $98 \%$ \\
2. & Negatif $(-)$ & 1 & $2 \%$ \\
\hline & Total & $\mathbf{7 3}$ & $\mathbf{1 0 0} \%$ \\
\hline
\end{tabular}

Sumber : Data Primer 2018

\section{PEMBAHASAN}

1. Hubungan Kebiasaan Memotong Kuku dengan Kejadian Infeksi Kecacingan Pada Pemulung Sampah di TPA Tamangapa Kota Makassar

Dari hasil uji statistik menggunakan chi square menunjukkan bahwa $p=0,000$ atau $p<0,05$, dimana ada hubungan antara memotong kuku dengan kejadian infeksi kecacingan pada pemulung sampah. Responden yang memiliki kriteria baik dan positif kecacingan sebanyak 1 responden $(50 \%)$, kriteria cukup dan positif kecacingan sebanyak 58 responden (100\%), serta kriteria kurang dan positif kecacingan sebanyak 13 responden (99\%) .

Kebiasaan memotong kuku pada penelitian ini adalah responden memotong kuku minimal satu kali dalam seminggu. Pemulung sampah yang memotong kuku dan membersihkan secara rutin 1 minggu sekali ,maka ia dikatakan selalu menjaga kebersihan kukunya. Namun, dalam penelitian ini kebanyakan pemulung memotong kukunya jika ada kesempatan ataupun bila sudah dirasa panjang, kondisi kuku tangan sebagian besar pemulung juga terlihat panjang dan kotor. $\mathrm{Hal}$ ini disebabkan karena masih kurangnya pengetahuan dan kesadaran responden terhadap dampak yang akan ditimbulkan apabila tidak memotong kuku secara rutin .

Penelitian ini sejalan dengan penelitian yang dilakukan oleh Gyne Kirsten Surfeki (2017) tentang hubungan personal hygiene, pemakaian alat pelindung diri dan sanitasi dasar rumah dengan kejadian kecacingan pada pemulung di sekitar TPA Parombunan Kota sibolga bahwa ada hubungan antara pemeliharaan tangan dan kuku dengan infeksi kecacingan dimana $X^{2}{ }_{\text {hit }}=24,47>X^{2}$ tabel $=3,841$, dari 55 responden ada 15 responden $(27,3 \%)$ yang positif kecacingan.

Penelitian ini juga sejalan dengan penelitian yang dilakukan oleh Ummul Waqiah ( 2015) tentang hubungan hygiene perorangan dengan kejadian infeksi kecacingan pada pemulung anak usia sekolah dasar di TPA Antang Makassar bahwa ada hubungan antara kebiasaan memotong kuku dengan kejadian infestasi kecacingan diman $X^{2}{ }_{\text {hit }}=5,52>X^{2}$ tabel $=$ 3,841 dari 63 responden yang memenuhi syarat memotong kuku sebanyak 29 responden $(46,1 \%)$ dan yang positif kecacingan sebanyak 21 responden $(39,6 \%)$,sedangkan yang tidak memenuhi syarat sebanyak 34 responden $(53,9 \%)$ dengan infeksi kecacingan sebanyak 32 oranng $(60,4 \%)$.

Meskipun para pemulung selalu mencuci tangan sebelum makan tetapi tidak terbiasa memotong kuku secara rutin yakni sekali dalam seminggu maka besar kemungkinannya untuk terinfeksi penyakit kecacingan karena telur cacing dapat masuk ke dalam tubuh melalui kotoran yang berada di bawah kuku pada saat makan.

2. Kebiasaan Mencuci Tangan dengan Kejadian Infeksi Kecacingan Pada Pemulung Sampah di TPA Tamangapa Kota Makassar

Dari hasil uji statistik menggunakan chi square menunjukkan bahwa $\mathrm{p}=0,000$ atau $p<0,05$, dimana ada hubungan antara mencuci tangan dengan kejadian infeksi kecacingan pada pemulung sampah. Responden yang memiliki kriteria baik dan positif kecacingan sebanyak 3 responden $(75 \%)$, kriteria cukup dan positif kecacingan sebanyak 50 responden (100\%), serta kriteria kurang dan positif kecacingan sebanyak 19 responden (99\%) .

Hal ini dibuktikan dengan kebiasaan responden tidak mencuci tangan dengan sabun setelah bekerja saat istirahat dan sebelum makan, namun ada beberapa responden hanya mencuci tangan dengan persediaan yang dibawa ke lokasi tempat mengumpulakan sampah tanpa menggunakan sabun, bahkan persediaan air yang dibawa kelokasi tersebut untuk mencuci tangan juga digunakan untuk dikonsumsi. Sehingga, besar kemungkinan telur cacing yang masih menempel pada tangan responden setelah bekerja karena 
berkontak langsung dengan tanah yang telah terkontaminasi telur atau larva cacing yang infektif dapat masuk bersama botol minuman yang juga digunakan sebagai pencuci tangan atau makanan yang dapat tertelan kedalam perut.

Penelitian ini sejalan dengan penelitian yang dilakukan oleh Surahma Asti M (2013) hubungan antara kebiasaan penggunaan alat pelindung diri dan personal hygiene dengan kejadian infeksi kecacingan pada petugas sampah dikota Yogyakarta bahwa ada hubungan antara kebiasaan mencuci tangan dengan infeksi kecacingan pada petugas sampah di kota Yogyakarta bahwa ada hubungan antara kebiasaan mencuci tangan dengan infeksi kecacingan dimana nilai $\mathrm{p}=0,015<0,05$ dari 44 responden sebanyak 15 responden (34,1\%) posotf kecacingan.

3. Kebiasaan Mandi dengan Kejadian Infeksi Kecacingan Pada Pemulung Sampah di TPA Tamangapa Kota Makassar

Dari hasil uji statistik menggunakan chi square menunjukkan bahwa $p=0,639$ atau $p>0,05$, dimana tidak ada hubungan antara kebiasaan mandi dengan kejadian infeksi kecacingan pada pemulung sampah. Responden yang memiliki kriteria baik dan positif kecacingan sebanyak 59 responden (98\%), kriteria cukup dan positif kecacingan sebanyak 13 (100\%), dan tidak ada (0\%) responden yang memiliki kriteria kurang.

Hal ini disebabkan karena sebagian besar pemulung telah mengenal dan menyadari akan pentingnya kebiasaan mandi yang baik seperti mandi dua kali sehari, mandi dengan menggunakan sabun dan menggosok badan, serta mandi saat badan berkeringat setelah melakukan aktivitas memulung merupakan salah satu tindakan preventif dalam mencegah terjadinya infeksi kecacingan.

Hasil Penelitian serupa juga didapatkan dalam penelitian Rizda Yunidha Anwar dkk (2013) tentang hubungan antara hygiene perorangan dengan infeksi cacing usus (Soil Transmitted Helmints) pada siswa SDN 25 dan 28 Purus yang menjadi responden menyatakan tidak ada hubungan antara kebiasaan mandi dengan infeksi cacing dengan nilai $P$ value $(0.753)>\alpha$ (0.05).

\section{Hubungan Kebiasaan Penggunaan Alat Pelindung Diri dengan Kejadian Infeksi Kecacingan Pada Pemulung Sampah di TPA Tamangapa Kota Makassar}

Berdasarkan uji statistik memperlihatkan nilai $p=0,004$, oleh karena itu $\mathrm{p}<0,05$ maka $\mathrm{H} 0$ ditolak dan $\mathrm{Ha}$ diterima yang berarti ada hubungan antara pemakaian APD dengan kejadian infeksi kecacingan pada pemulung sampah. Responden memenuhi syarat pemakain APD dan positif kecacingan sebanyak 7 responden $(88 \%)$ serta tidak memenuhi syarat pemakaian APD dan positif kecacingan sebanyak 65 responden (100\%).

Hal ini disebabkan karena kebiasaan responden pada saat bekerja (memulung) memiliki kecenderungan tidak terbiasa menggunakan APD lengkap sehingga resiko terinfeksi cacing sangat besar. Adanya hubungan yang bermakna antara penggunaan APD dengan kejadian infeksi cacing membenarkan bahwa APD sangat penting. Responden pemulung di TPA Tamangapa saat bekerja sering tidak memakai sarung tangan dan alas kaki. Berdasarkan hasil penelitian yang telah dilakukan, kebanyakan responden tidak nyaman memakai sarung tangan saat bekerja memilah sampah. Memakai sarung tangan dapat membuat waktu bekerja mereka menjadi lama. Responden dalam pemakaian alas kaki juga sangat sedikit dikarenakan minimnya pendapatan mereka sehari-hari untuk membeli sepatu booth.

Penelitian ini sejalan dengan penelitian yang dilakukan oleh Lezdyana Nur Islami (2014) tentang hubungan penggunaan alat pelindung diri dengan kejadian infeksi cacing pada pekerja sampah menunjukkan bahwa terdapat hubungan antara penggunaan APD dengan kejadian infeksi cacing berdasarkan uji Chi Square didapatkan nilai $P=0,04$.

Penelitian ini juga sejalan dengan Amelia Pratiwi (2017) tentang Gambaran Hygient Perorangan dan Pemakaian Alat Pelindung Diri menunjukkan bahwa yang menunjukkan bahwa ada hubungan antara perilaku penggunaan APD dengan infeksi cacing berdasarkan uji Chi Square didapatkan nilai $P=0.000$ ). 


\section{Infeksi Kecacingan}

Berdasarkan hasil pemeriksaan di laboratorium parasitologi yaitu Ascaries sebanyak 45 responden dengan persentase (62\%), kemudian Trichius yang ditemukan pada 23 responden dengan persentase (31\%) dan yang paling sedikit adalah Ancylostoma + Necator yang ditemukan pada 5 responden dengan persentase $(7 \%)$.

Hasil penelitian ini menunjukan bahwa angka kejadian infeksi kecacingan pada pemulung sampah di TPA Tamangapa sangat tinggi. Hal ini karena pada saat penelitian dan dilakukan wawancara pada para pemulung sampah, didapatkan informasi bahwa para pemulung sampah sangat jarang meminum obat cacing,mereka hanya mengkonsumsi obat cacing apabila ada petugas kesehatan atau apabila merasakan gejala kecacingan. Hal ini disebabkan karena pemulung sampah yang terinfeksi cacing setiap hari berada di tempat yang kondisi lingkungannya kurang baik yakni tempat sampah dimana para pemulung sampah setiap hari selalu kontak dengan sampah dan pada saat melakukan kegiatan seperti makan, minum dan istirahat selalu berada dekat dengan tempat sampah ini merupakan tempat berkembangbiaknya bibit penyakit tidak terkecuali sampah yang terkontaminasi telur atau larva cacing yang infektif.

Penelitian ini sejalan dengan penelitian yang dilakukan oleh Kartika,dkk (2016) tentang Hubungan Perilaku Bersih dan Sanitasi Lingkungan Terhadap Kecacingan pada Pemulung TPA Jatibarang Semarang menunjukkan dari 120 responden diperoleh dari hasil pemeriksaan tinja bahwa prevelensi kecacingan sebesar 47,5\% prevelensi tertinggi Ascariasis 52,6\%.

Penelitian ini juga sejalan dengan Amelia Pratiwi (2017) tentang Gambaran Hygient Perorangan dan Pemakaian Alat Pelindung Diri Dari hasil pemeriksaan tinja pada pemulung sampah di TPA Tamangapa
(2017) responden yang positif infeksi kecacingan Ascaris lumbricoides 20 orang $(64,5 \%)$, Trichuris trichiura) 5 orang $(16,0 \%)$ dan Cacing tambang (Ancylostoma \& Necator) 2 orang $(6,6 \%)$

\section{PENUTUP}

1. KESIMPULAN

Kesimpulan dari penelitian ini adalah infeksi kecacingan tidak berhubungan dengan kebiasaan mandi, akan tetapi, berhubungan dengan kebiasaan mencuci tangan, kebiasaan memotong kuku, dan pemakaian APD.

\section{SARAN}

\section{a. Bagi Pemulung}

Para pemulung diharapkan agar memperhatikan hygiene perorangan saat selesai bekerja di Tempat Pembuangan Akhir sampah Tamangapa Kota Makassar.

\section{b. Bagi Dinas Kebersihan Dan Pertamanan Kota Makassar}

Dinas Kebersihan Dan Pertamanan Kota Makassar, serta Pengelolah TPA Tamangapa diharapkan dapat menyediakan APD dan memberikan informasi atau meberikan penyuluhan terhadap pemulung di lokasi TPA untuk pemakaian Alat Pelindung Diri (APD) guna terhindar dari kecelakaan kerja dan penyakit bawaan sampah seperti Infeksi kecacingan yang sering terjadi di TPA.

c. Bagi Dinas Kesehatan Kota Makassar Dinas Kesehatan Kota Makassar diharapkan melakukan program pencegahan kejadian kecacingan melalui pemeriksaan feces rutin ,melakukan program penyuluhan dan pengobatan serta pemberian obat cacing pada pemulung yang bekerja di Tempat Pembuangan Akhir (TPA) Tamangapa Kota Makassar.

\section{DAFTAR PUSTAKA}

Adhi Kumoro Setya. 2014. Parasitiologi Praktikum Analis Kesehatan. Jakarta: EGC

Akhsin Zulkoni. 2011. Parasitiologi untuk Keperawatan, Kesehatan Masyarakat dan Teknik Lingkungan. Yogyakarta: Nuha Medika. 
Jurnal Sulolipu : Media Komunikasi Sivitas Akademika dan Masyarakat

Vol. 18 No 22018

e-issn : 2622-6960, p-issn: 0854-624X

Amelia Pratiwi. 2017. Gambaran Hygiene Perorangan dan Pemakaian Alat Pelindung Diri Pada Pemulung Sampah TPA Tamangapa Antang Kota Makassar. Universitas Muslim Indonesia Fakultas Kesehatan Masyarakat. (Skripsi Tidak Dipublikasikan)

Anizar. 2010. Teknik Keselamatan dan Kesehatan Kerja di Industri. Yogyakarta: Graha Ilmu.

Arpan Tombili dan Rizky Mardewi. 2010. Study Pengetahuan, Sikap dan Tindakan Tentang Alat Pelindung Diri pada Petugas Pengumpul Sampah di Dinas Kebersihan Kota Kendari. (online). http://www.academia.edu/. Diakses pada tanggal 05 Januari 2018

Cynthia Agustini. 2016. Hubungan Antara Personal Hygiene dengan Gambaran Telur Soil Transmitted Helminths (STH) pada Kuku Jari Tangan Siswa SDN 27 Anak Air, Kota Tangah, Padang. Skripsi. Fakultas Kedokteran dan IImu Kesehatan. Universitas Andalas Padang.(Online).http://scholar.unand.ac.id/ . Diakses pada tanggal 17 Desember 2017

Depkes.1990. Penanggulangan Penyakit Cacing. Jakarta: Departemen Kesehatan Republik Indonesia.

Dewi Puspa Rianda. 2014. Pengetahuan dan Tindakan Personal Hygiene Pemulung Sampah di TPA Ganet Tanjung Pinang. Jurnal Kesehatan. 5 (2): 162 - 166. (online). http:// poltekkes -tjk. ac. id/. Diakses pada tanggal 28 Desember 2017.

Elmer R. dan Noble. 1989. Parasitiologi Biologi Parasit Hewan. Jogjakarta: Gadjah Mada University Press.

Faras Handayani.2017. Hati - Hati Cacing Menular. (online). http:// press reader.com//. Diakses pada tanggal 20 Desember 2017

Ganda husada. S. 2004. Parasitiologi Kedokteran. Jakarta: Fakultas Kedokteran Universitas Indonesia.

Hendra Widodo.2013. Parasitiologi Kedokteran. JogJakarta: D-Medika.

IrhamSiregar,dkk.2013. Hubungan Personal Hygiene dengan Penyakit Cacing (Soil Transmitted Helminths) pada Pekerja Tanaman Kota Pekanbaru. Jurnal Kajian Lingkungan. 1 (1): 93-102. (online). http://ejournal.unri. ac.id/. Diakses pada tanggal 24 Desember 2017.

Kartika Ikawati, dkk. 2016. Hubungan Perilaku Hidup Bersih dan Sanitasi Lingkungan terhadap Kecacingan pada Pemulung. Jurnal Keperawatan dan Kesehatan Masyarakat.2 (4): 63-73. (online). http:// jurnal. Stikes cendekia utama kudus.ac.id//. Diakses pada tanggal 18 Desember 2017

KoesIrianto.2009. Panduan Praktikum Parasitiologi Dasar. Bandung: Yrama Widya.

Laily Isro'in. 2012. Personal Hygiene. Jakarta: Graha IImu.

Lezdyana Nurlslami, dkk. 2014. Hubungan Penggunaan Alat Pelindung Diri dengan Kejadian Infeksi Cacing pada Pekerja Sampah. Jurnal.2 (1): 109-112. (online). http://ojs,uho.ac.id/. Diakses pada tanggal 22 Desember 2017

Musfira Abdulla. 2016. Hubungan Perilaku Hygiene Perorangan dengan Infeksi Kecacingan Pada Pemulung Sampah di TPA Antang Kota Makassar. Poltekkes Kemenkes Makassar Jurusan Kesehatan Lingkungan. (KTI Tidak Dipublikasikan).

Notoadmodjo, Soekidjo. 2003. Pendidikan dan Perilaku Kesehatan. Jakarta: Rineka Cipta.

Republik Indonesia. 2010. Peraturan Tenaga Kerja dan Transmigrasi Republik Indonesia Nomor 08 Tahun 2010 tentang Alat Pelindung Diri. Kementerian Tenaga Kerja dan Transmigrasi Republik Indonesia 
Jurnal Sulolipu : Media Komunikasi Sivitas Akademika dan Masyarakat

Vol. 18 No 22018

e-issn : 2622-6960, p-issn: 0854-624X

Rizka Yunidha Anwar, Nuzulia Irawati, dan Machdawaty Masri. 2013. Hubungan antara Hygiene Perorangan dengan Infeksi Cacing Usus (Soil Transmited Helmints) padaSiswa SDN 25 dan 28 Kelurahan Purus, Kota Padang.Jurnal Kesehatan Andalas. 5 (3): 600-607. http://jurnal.fk.unand.ac.id/. Diakses pada tanggal 27 Desember 2017.

Sugeng Budiono, dkk. 2003. Hiperkes dan KK Edisi ke II. Semarang: BP Universitas Diponegoro.

Suma'mur.P.K. 1989. Keselamatan Kerja dan Pencegahan Kecelakaan. Jakarta: PT.Gunung Agung.

Surahmah Asti Mulasari dan Damaiyanti Maani. 2013. Hubungan Antara Kebiasaan Penggunaan Alat Pelindung Diri dan Personal Hygiene dengan Kejadian Infeksi Kecacingan pada Petugas Sampah di Yogyakarta.Jurnal Ekologi Kesehatan. 12 (2): 161-170. (online). http://ejournal.litbang.depkes.go.id/. Diakses pada tanggal 08 Januari 2018

Tasiana. 2009. Definisi Pemulung. (online) http://ektasia.com/. Diakses pada tanggal 10 Januari 2018.

Ummul Waqiah. 2016. Hubungan Hygiene Perorangan dengan Kejadian Infeksi Kecacingan Pada Pemulung Anak Usia Sekolah Dasar di TPA Antang Makassar. Universitas Islam Negeri Alauddin Fakultas Kesehatan Masyarakat. (Skripsi Tidak Dipublikasikan)

WHO. 2011. Soil transmitted helminth infections. (online).http://www.who.int/. Diakses pada tanggal 10 Januari 2018

WHO. 2015. World Health Organization anda partners unveils new coordinate approach to treat millions suffering from neglected tropical diseases. (online). http://www.who.int/. Diakses pada tanggal 12 Januari 2018

Wiwik Mulyani. 2012. Pemulung. (online). http://wiwikmulyani.blogspot.com// . Diakses pada tanggal 13 Januari 2018.

Zulfiana Riswanda. 2017. Hubungan Infeksi Soil Transmitted Helminth (STH) dengan Pertumbuhan dan Status Anemia Siswa Sekolah Dasar Negeri di Kecamatan Kelumbayan Kabupaten Tanggamus. Skripsi. Fakultas Kedokteran. Universitas Lampung. (online). http://digilib.unila.ac.id/. Diakses Pada tanggal 14 Januari 2018. 